\title{
Prednisolone Acetate
}

National Cancer Institute

\section{Source}

National Cancer Institute. Prednisolone Acetate. NCI Thesaurus. Code C1202.

The acetate salt form of prednisolone, a synthetic glucocorticoid with anti-inflammatory and immunomodulating properties. As a glucocorticoid receptor agonist, prednisolone acetate binds to specific intracellular glucocorticoid receptors, and causes the ligandreceptor complex to be translocated to the nucleus where it initiates the transcription of glucocorticoid-responsive genes such as various cytokines and lipocortins. Lipocortins inhibit phospholipase A2, thereby blocking the release of arachidonic acid from membrane phospholipids and preventing the synthesis of prostaglandins and leukotrienes, both potent mediators of inflammation. This agent also decreases the number of circulating lymphocytes, induces cell differentiation, and stimulates apoptosis in sensitive tumor cell populations. 